\title{
Continuous axillary nerve block for chronic pain
}

\author{
M S Fewtrell, D J Sapsford, M J Herrick, G Noble-Jamieson, R I Ross Russell
}

\begin{abstract}
Continuous axillary nerve block was used to relieve pain after a chemical burn to the arm in a child on mechanical ventilation after liver transplantation. The analgesia was sufficient to replace parenteral analgesia and allow extubation.

(Arch Dis Child 1994; 70: 54-55)
\end{abstract}

Although the technique of continuous brachial plexus blockade is well established in adult anaesthetic practice for upper limb surgery and the treatment of chronic pain, there are few reports of its use in children. We found the technique helpful in an infant who sustained a chemical burn to her hand after major surgery. The block enabled us to withdraw parenteral analgesics and assisted weaning from ventilation.

\section{Case report}

An 11 month old girl weighing $7 \mathrm{~kg}$ with biliary atresia and abdominal situs inversus underwent orthoptopic liver transplantation. The operation was particularly difficult technically; blood losses were large and intravenous access difficult. During the operation an infusion of aprotinin (Trasylol, Bayer) was given through a 21 gauge cannula in the dorsum of the right hand, but this leaked into the tissues shortly afterwards. Small volumes of $10 \%$ calcium chloride had been infused through the same cannula before the aprotinin, under close observation and with no visible complications. The hand became swollen and blue with poor peripheral perfusion. A full thickness burn with subcutaneous and vascular calcification developed, with calcification extending along the forearm. The limb was obviously painful, and morphine in a dose of $80 \mu \mathrm{g} / \mathrm{kg} /$ hour was required, resulting in respiratory depression and difficulty weaning the child from the ventilator.

Eighteen days postoperatively a brachial plexus block was performed using the axillary approach. An 18 gauge insulated needle was inserted under sterile conditions, using a nerve stimulator to locate the axillary sheath. Once located, $3 \mathrm{ml}$ of $0.25 \%$ bupivacaine in $10 \mathrm{ml}$ saline was injected, producing a full block with improved perfusion. A catheter was inserted to $4 \mathrm{~cm}$ (Braun Contiplex, $0.85 \mathrm{~mm}$ external diameter). Analgesia was maintained with a continuous infusion of bupivacaine and diamorphine in normal saline $(0.5 \%$ bupivacaine $15 \mathrm{ml}+$ diamorphine $1 \mathrm{mg}$ diluted to 50 $\mathrm{ml}$ with normal saline, at $2 \mathrm{ml} /$ hour; equivalent to bupivacaine $0.43 \mathrm{mg} / \mathrm{kg} / \mathrm{hour}$ ).

After the procedure the child was more settled, parenteral analgesics were stopped, and she was successfully weaned from ventilation. The burn was debrided six days later without additional perioperative analgesia. The catheter was removed after 10 days. There were no complications, and the catheter tip was sterile on culture.

\section{Discussion}

The technique of continuous brachial plexus block was first described by Ansbro in 1946, 1 and its use in producing vasodilatation and providing pain relief in adults is now well documented. There are three possible approaches to the plexus, of these, the axillary route carries a lower risk of pneumothorax and phrenic nerve damage. Vascular damage is less likely when a nerve stimulator is used to locate the nerve sheath.

In the past decade, the use of regional anaesthesia in children has increased, although largely for analgesia in the immediate postoperative period. The role of regional blocks to relieve chronic pain and/or to improve vascular compromise remains to be established. There are two reports on the use of caudal ${ }^{2}$ or lumbar ${ }^{3}$ block in the management of lower limb ischaemia associated with meningococcaemia. In addition, lumbar sympathectomy proved beneficial in four children with vascular compromise secondary to extravasated intravenous drugs. ${ }^{4}$ Reports of continuous brachial plexus blockade in children are even more scarce. Lagade et al used a stellate ganglion block to relieve vascular insufficiency in a $1600 \mathrm{~g}$ infant after accidental intra-arterial drug administration, with apparent improvement. ${ }^{5}$ Finally, axillary nerve blockade was used for acute vascular compromise after surgery for the repair of radial club hands in a 7 month old infant. ${ }^{6}$

In our patient, the technique was chosen primarily for analgesia, as her high opiate requirement was felt to be interfering with attempts to wean ventilation. However, it also had an obvious beneficial effect on limb perfusion, and would probably have had a part to play immediately after the injury, had the child's coagulation not been grossly deranged. The procedure was well tolerated, and we encountered no complications, despite the catheter remaining in situ for 10 days in an immunosuppressed patient. We were surprised by the degree of damage produced by the extravasation of aprotinin, as the manufacturer's instructions warn only of occasional thrombophlebitis. Although calcium chloride had previously been infused into the same cannula there had been no obvious swelling or discoloration, and the line was flushed easily with saline before the aprotinin infusion was commenced. The patient's general condition 
at the time of the accident, however, was such that hypotension and tissue hypoxia may well have contributed significantly to the final injury.

We made no attempt to monitor serum bupivacaine concentrations in our patient. Pharmacokinetic studies of continuous bupivacaine infusion for up to 72 hours postoperatively, via the lumbar epidural ${ }^{7}$ and intrapleural ${ }^{8}$ routes in children, have shown non-toxic plasma concentrations, with no evidence of accumulation. The maximum dose used in these studies, $2.5 \mathrm{mg} / \mathrm{kg} / \mathrm{hour}$, is significantly greater than that received by our patient. In addition, the absorption of local anaesthetic depends on the vascularity of the site, being greater for intrapleural and epidural blocks than for those of the brachial plexus. We did not, therefore, anticipate problems with bupivacaine toxicity, particularly as our patient's renal and hepatic function were normal at the time of the procedure.

Diamorphine was added to the block because there is evidence that perineurally injected opiates are effective in the treatment of chronic pain. ${ }^{9}$ The mechanism of this effect, whether a direct action on the nerve or due to diffusion of drug into the epidural space where it acts on the substantia gelatinosa of the dorsal horn, remains unclear. Certainly the dose of diamorphine that we used was too small to have any significant systemic effect.
Combining the two drugs in this manner enabled smaller doses of each to be used, further reducing the risk of toxicity.

In summary, continuous brachial plexus blockade via the axillary route is a safe, effective technique. In addition to its role in upper limb surgery, it should be considered in patients with chronic pain, particularly those in whom respiratory depression from opiates is causing problems, and also in patients with acute vascular compromise.

1 Ansbro FP. Method of continuous brachial plexus block. Am I Surg 1946; 71: 16-22.

2 Tobias JD, Haun SE, Helfaer M, Nichols DG. Use of continuous caudal block to relieve lower extremity ischaemia caused by vasculitis in a child with meningococcaemia. F Pediatr 1989; 115: 1019-21.

3 Anderson CTM, Berde CB, Sethne NF, Pribaz JJ. Meningococcal purpura fulminans: treatment of vascular insufficiency in a 2 year old child with lumbar epidural insufficiency in a 2 year old child with lumbar epidura

4 Sanchez V, Segedin ER, Moser M, Pallares VS. Role of lumbar sympathectomy in the paediatric intensive care
, setting. Anesth Analg 1988; 67: 794-7.

5 Lagade MRG, Poppers PJP. Stellate ganglion block: a therapeutic modality for arterial insufficiency of the arm in premature infants. Anesthesiology 1984; 61: 203-4.

6 Audenaert SM, Vickers H, Burgess RC. Axillary block for vascular insufficiency after repair of radial club hands in an infant. Anesthesiology 1991; 74: 368-70.

7 Desparmet J, Meistelman C, Barre J, Saint-Maurice C. Continuous epidural infusion of bupivacaine for postoperative pain relief in children. Anesthesiology 1987; 67: operative

8 McIlvaine WB, Knox RF, Fennessey PV, Goldstein M. Continuous infusion of bupivacaine via intrapleural catheter for analgesia after thoracotomy in children. Anesthesiology 1988; 69: 261-4

9 Mays KS, Lipman J, Schnapp M. Local analgesia without anaesthesia using peripheral perineural morphine injections. Anesth Analg 1987; 66: 417-20. 